\title{
Pharmacy in Basel
}

\author{
Michael Kessler*
}

\begin{abstract}
The production of pharmaceuticals is one of the foundations of the economy and financial stability of the Basel region. Pharmacy and the city of Basel have been synonymous, and historically entwined, for a considerable time. Probably no other city in the world displays a higher density of pharmaceutical industry. The historic origins of these developments stem from far back in the Middle Ages. However, the past two hundred years have transformed our medical and pharmaceutical sciences tremendously, and this progress has made deep impressions upon Basel's industry. The predominant sources and currents that have influenced the foundation and development of the Basel pharmaceutical industry are described in this article. The histories of pharmacy and medicine are definitively connected, and neither subject can be properly understood without the awareness of the relationship between the two. Pharmacy and medicine were affected by diverse cultural influences and sociological changes, and further by profound advances in the natural sciences and the resultant technological discoveries. Today's pharmaceutical industry in Basel is a living illustration of the combined complexity of a distant historical past and the technological present working together towards the future.
\end{abstract}

Keywords: Drug industry $\cdot$ History of medicine $\cdot$ Pharmacy $\cdot$ Textile industry

\section{The Production of Pharmaceuticals as a Basis for Regional Economy and Financial Stability}

Pharmacy and the city of Basel in Switzerland have been synonymous and historically entwined for a very long time. Probably no other city in the world displays a higher density of pharmaceutical industry. The historic origins of these developments stem from far back in the Middle Ages. However, the past two hundred years have transformed our medical and pharmaceutical sciences tremendously, and this progress has made deep impressions upon Basel's industry. The times of artful prescriptions, of theriacs and home remedies are long past, and have been replaced by state-of-the-art production on an industrial scale.

\footnotetext{
${ }^{*}$ Correspondence: Dr. M. Kessler

University of Basel

Pharmacy Museum

Totengässlein 3

$\mathrm{CH}-4051$ Basel

Tel.: + 41612649114

Fax: + 41612649112

E-Mail: Michi.Kessler@unibas.ch
}

Under the consistent influence of a multitude of variable factors from the development of the natural sciences and related technological advances, the history of pharmacy has altered its appearance with time although the basis for its definition lies in the changing attitude towards health, illness, and medicine over the course of time. So if one is to consider the history and presence of pharmacy in Basel, one has to first clarify the medico-historical background of this development.

The drive to heal illnesses is as old as mankind. Yet religious and sociological backgrounds at the time have always been decisive factors influencing the forms into which medicine and therapy were moulded. It is clear that occidental medicine has developed from the realisations of classical European culture, although enriched by major influences from the exterior, and subject to many influences and transitions through the course of history, including certain fundamental discoveries and realisations made in classical times that have remained valid through to the modern era. Since the Middle Ages, medicine has begun to evolve in a new direction. The fact that discoveries in the natural sciences have increased tremendously since the times of the Renaissance has greatly influenced medical therapy. By understanding the human body better, the attempts to influence it therapeutically became more accurately targeted and specific.

In parallel to the natural sciences, the technical sciences have also developed very swiftly. Since the end of the 18th century, medicine has breached an ever broader development bracket and, since the time of industrialisation, has continuously started to utilise new scientific and technical methods. Pharmacological therapy has perhaps undergone this development even more so. With the technical methods of the 19th century, a totally new, standardised and industrial medicine production became possible. Taking this into account, it is possible to follow the creation of modern western medicine.

\section{The Apothecary Profession in Basel During the Late Medieval and the Renaissance Periods}

During the high and late medieval period, Basel was already a significant and important European city. Through its favourable position on the Rhine, situated at the great connecting axes of the North-South upper Rhine basin and the East-West Burgundy gateway, Basel became an extraordinarily wealthy trading centre. In matters of religion, Basel was a city of the church and a sacred place of worship of the Virgin Mary; with powerful clerical institutions (Council of Basel) and rich monasteries. With this background as a foundation, Basel's apothecary profession has a proud and remarkable past. The manufacture of drugs by craftsmen, and the trade in medicines and spices brought substantial wealth. The 
apothecary profession had been organised within the Basel Saffron Guild since the 14 th century and therefore had a significant political influence. In the late middle ages, Basel was indeed a town of guilds. The citizens, rich masters of craft and the developing local aristocracy gradually took over power from the church, diminishing the influence of the bishop of Basel. A representative example of this development is Henmann von Offenburg (1379-1459), the son of a Basel apothecary, who became an apothecary himself and member of the Saffron Guild (Fig. 1). Then, in 1423, he founded the first Basel trade association. He was knighted in 1433 and became the Grand Master of the Guilds and Alderman. As a Master Trader, merchant and diplomat he played a significant role during the time of the Council of Basel.

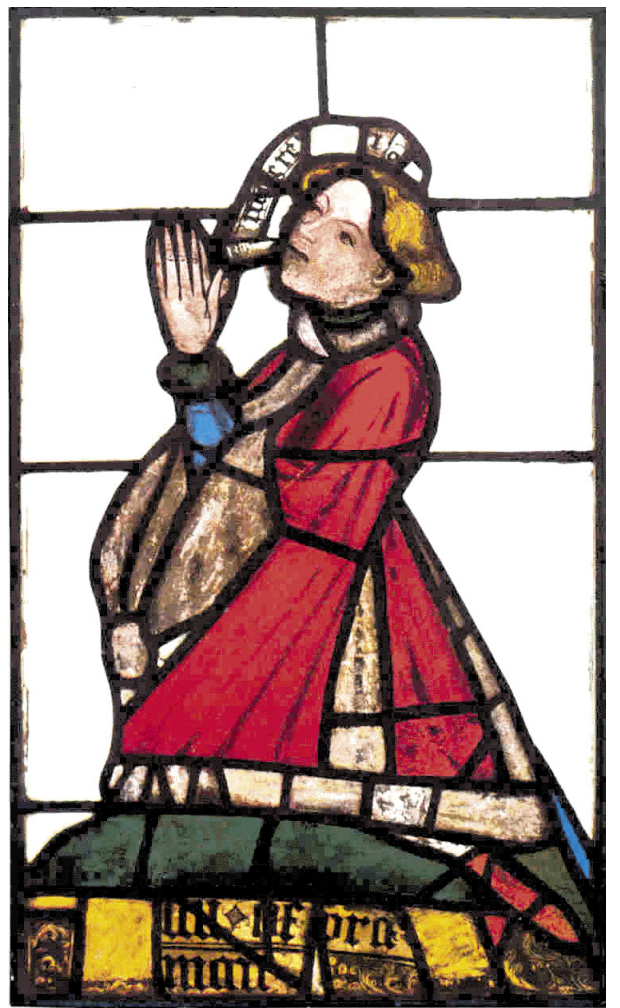

Fig. 1. Henman von Offenburg, Apothecary and Grand Master the Guilds of Basel. The stained glass window of the Karthäuserkirche dates from 1416 and is the earliest depiction from the German speaking Apothecary profession. (Basel Historical Museum)

During the Renaissance, the dawning of the modern era caused a metamorphosis in all areas of political, sociological, and clerical thought and life: This transformation of the worldview became evident in medicine and medical science. The concept of medieval medicine was heavily infused with religious doctrine; from cleansing of the soul to God's punishments for sinful living. The running of hospitals was limited to and controlled by the monasteries and was based on the concept of charity. The search for the causes of illness and thus rational therapies was very limited. Only with the change to an anthropocentric worldview during the renaissance and concentration on the human body was the path opened to a new understanding of illness and healing. The role of anatomy became central and obvious during this crucial phase of development.

Because of its great importance as a centre of book printing during the Renaissance, Basel also became an epicentre of cultural development. Printers with broad European continental experience and personal charisma were drawn to working in Basel as printers and publishers, in particular Johannes Frobenius, the king of European printers. These men were able to attract the leading scholars to Basel for their books to be printed. As such, Erasmus von Rotterdam (Fig. 2) spent two years of his life in Basel. Erasmus is considered to have been one of the greatest intellectual authorities in Europe at the time. He lived for two years as a guest in the house of his friend, Johannes Froben, at Totengässlein (Fig. 3).

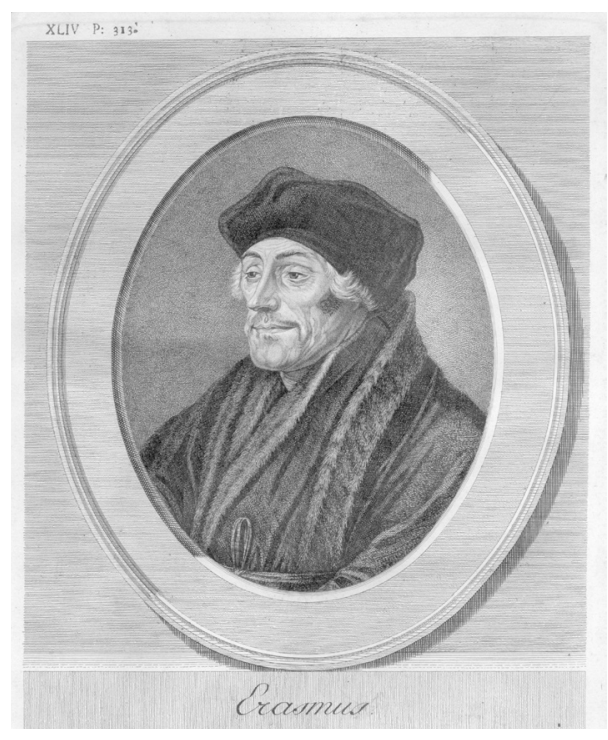

Fig. 2. Erasmus von Rotterdam (1469-1536)

Of great significance to medicine and pharmacy was another guest who frequented Froben's home. In the year 1526, the printer sent for the then already famous doctor, Theophrast von Hohenheim (Fig. 4), who named himself Paracelsus. After being successfully cured, Froben then gave his support to Theophrast von Hohenheim. With this promotion, von Hohenheim became the medical officer of Basel. The significance of Theophrast von Hohenheim for the development of medicine and pharmacy is considerable. He was the first person to introduce chemistry, which had been taken over from the Orient as Alchemy, into medicine. $\mathrm{He}$ understood medical phenomena as an expression of chemical processes and there-

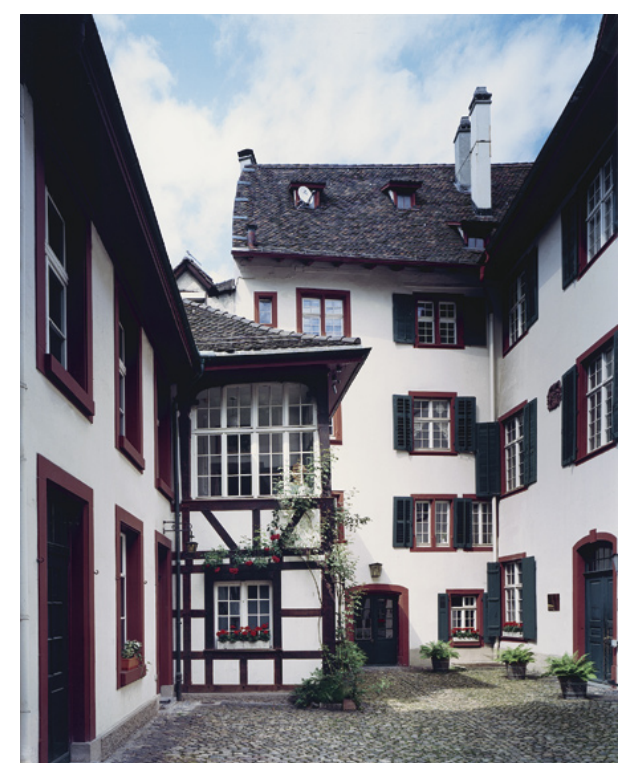

Fig. 3. The 'Haus zum Sessel' at Totengässlein in Basel. The printer Johannes Froben and his famous guests Erasmus von Rotterdam and Theophrast von Hohenheim, named Paracelsus, lived and worked here. In the 20th century it was home to the Pharmaceutical Institute as well as the Museum of Pharmacy of the University of Basel, which is still at this location today.

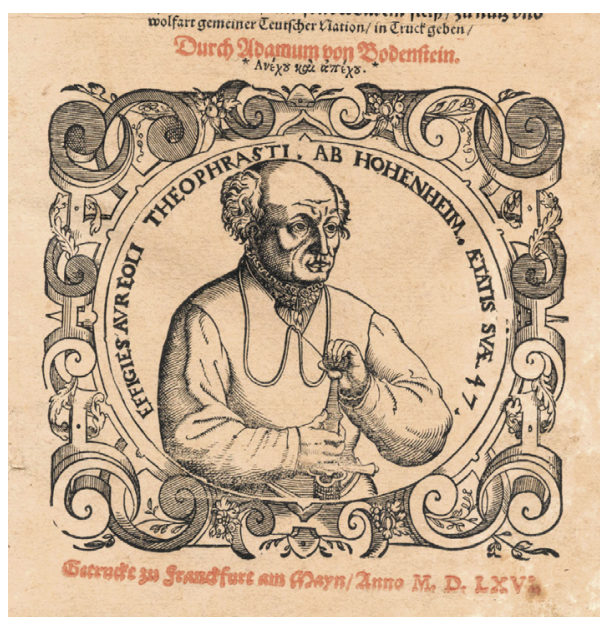

Fig. 4. The Great Wound Remedy (Die grosse Wundarznei), or Opus chyrurgicum. The main work of Paracelsus on medicine. (Museum of Pharmacy of the University of Basel)

fore his realisations caused a turning point in occidental pharmacotherapy.

\section{Textile Production and the Rise of the Chemical Industry}

In the centuries after the Renaissance era, the attitude towards nature was marked more and more by rational knowledge, logical argument and observation. This paved the way for the emergence of the modern sciences in the 18th century. The focus was on observation and description; the results were then rationally discussed and linked. 
Things were seen and clarified in context. Data was collected and edited into encyclopaedia, and thus distributed throughout Europe. Towards the end of the 18th century, the application of new innovations and realisations in craft, trade and production finally initiated a massive development in many areas of technology. This gave the starting signal of the industrial revolution of the 19th century. This evolution had tremendous consequences for the city of Basel.

Until the breakdown of the Ancien Régime in the year 1798 the guilds stringently controlled the market and made sure that no foreign products entered the city's market. However in the 16th and 17 th centuries, numerous religious refugees from Italy, Germany, the Netherlands and particularly France settled in Basel. They were wealthy craftsmen and merchants with good trades and connections. Thus, with these Huguenots, silk manufacture entered Basel.

Immigrant merchants from France and Germany expanded the fabrication of silk ribbon with the assistance of the country peasantry (Fig. 5). The normally tight barrier system of the Basel guild orders was circumvented, and instead an export business on a large scale was created. Since the 17 th century a distributing system involving cottage industry began to evolve. The manufacturers, or Ribbon Masters, procured the raw material at big fares and markets, and had them woven into ribbons by the outworkers, or 'Basamenter'. Through this flourishing system of business, the Ribbon Masters achieved great wealth and respect.

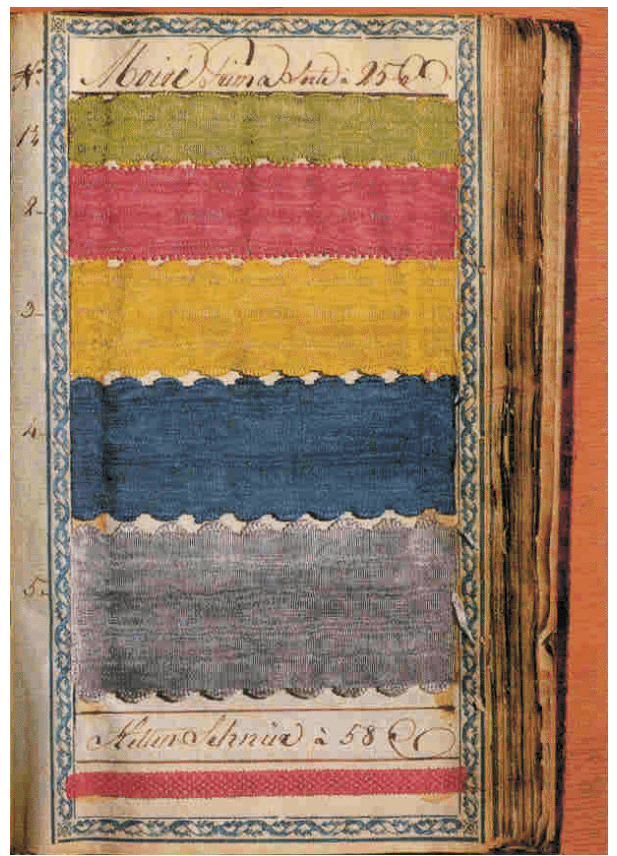

Fig. 5. A sample of silk ribbons by the company of Emanuel Hoffmann, 1780. (Basel Historical Museum)

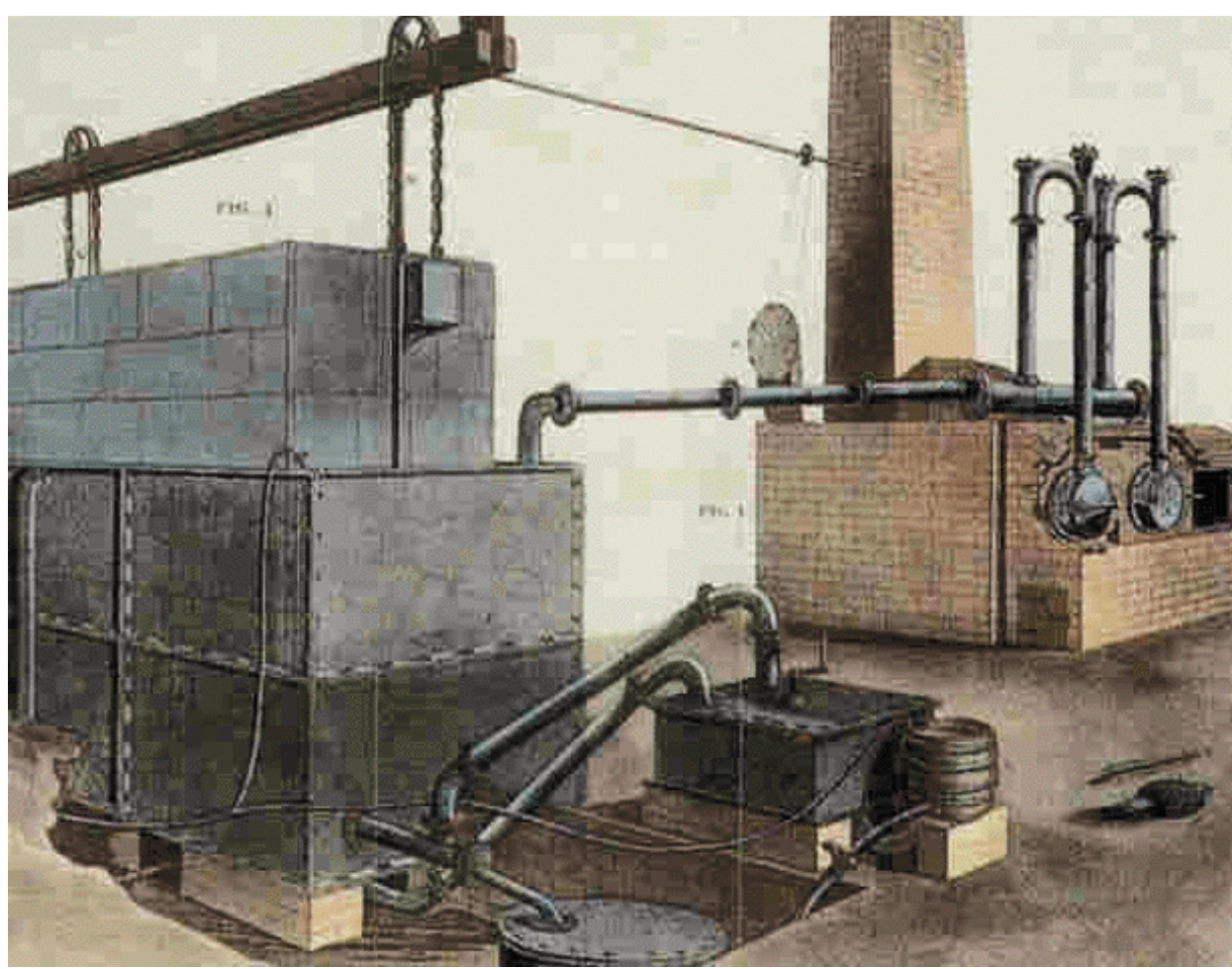

Fig. 6. Production of lighting gas, from 'A Practical Treatise on Gas-Light', London 1816.

The 19 th century brought the silk ribbon industry several important technological advances, for example, the Jacquard-loom (introduced in 1820) that was steered with a punch card system. Around 1870, the Basel ribbon industry reached its pinnacle. In the 19th century, the substantial means of the manufacturers finally formed the basis for the foundation of new industrial sectors for the Basel region.

After the partition of Basel City (Basel-Stadt) and Basel Country (Basel-Landschaft) in 1833, the old conservative circles prevailed again in the governing bodies. The guilds were able to expand their influence once again, but later their power was limited with the federal constitution in 1848 . In the total revision of 1874 , the guilds lost their power in politics and jurisdiction completely. From this point onwards free business and trade were finally able to proceed in Basel.

Since the beginning of the 19th century, the sale of goods increased together with the rise in the population in Europe. The old production methods did not suffice to satisfy the growing market demands. Through science and technology new production processes were sought and researched. In the production of steel, charcoal was replaced by mined coal; being richer in energy this made sense, but inconvenient due to the biproduct or waste product, coal tar. However, trials showed that further substances could be derived from coal tar. These substances became the most important raw materials in the whole of the chemical industry. For example, it was possible to extract aniline from this tar, the base material for the tar colours named after it.

In the year 1852, gas lighting was introduced in Basel, as had already happened in many other European cities (Fig. 6). In St. Alban-Vorstadt, the first small gas factory came into existence. However the strong demand made it necessary to enlarge and finally transfer it to the front of the St. Johanns-Tor. The coal tar resulting in great quantity as a waste product from the transformation of mined coal into gas became an important raw material for the emerging chemical and pharmaceutical industry in Basel.

Up to this point, the colours used in textile manufacture had been derived exclusively from natural plant- or animalbased products (blue from indigo, red from krapp), which were extracted in small quantities mostly directly at the dye works. In 1856, the English chemist William Henry Perkin (1838-1907) succeeded in making aniline purple, so-called mauvein, from coal tar. For the first time, dyes could now be synthesised at good prices. Real success however came with the development of the red dye fuchsin. In 1859, in the laboratory of the silk dye works of Renard in Lyon, this tar colour was synthetically produced with success. Immediately, fashion took on this new colour. Fuchsin was the first dye to be produced in a large technological plant. Patents in France and England protected the production process. After these initial first colours, the colour palette expanded rapidly, with the increasing rationalisation and production of colours in large techno- 
logically specific and designed factories, most of which sprung from the original dye works. This process made it possible to bring down production costs; and, as a result dyes became cheaper.

The seed for crystallisation of the chemical industry in Basel was the dye fuchsin. Fuchsin and other foreign inventions, including production methods, could be reproduced in Switzerland by Swiss firms, irrespective of foreign patents, without the necessity to pay compensation. This was because Switzerland only introduced a Patents Law in 1888. In 1859, the same year that the synthesis of fuchsin was achieved, Alexander Clavel (1805-1873) built a factory for the industrial production of this dye in the middle of Basel. Clavel was the father-in-law of Joseph Renard and was able to take over the production method. Thus, he became the first and most important producer of aniline colours in Switzerland. In 1864 , he transferred production to his new 'Laboratory for the Manufacture of Aniline and Other Colours', (Laboratorium für Fabrikation von Anilin- und anderen Farben"), at Klybeckstrasse on the Rhine. It was subsequently purchased by the firm Bindschedler \& Busch in 1872. From this firm grew the Association for Chemical Industry Basel, CIBA.

The Basel Gas Factory, founded, in 1860, with its linked tar colour factory (1862), was another pillar of the chemical industry. This firm, Durand-Huguenin, transferred to the firm Sandoz in 1969.

These favourable production conditions allowed the production and trade in dyes to flourish in Basel. Specialised delivery firms were engaged to smuggle considerable quantities of contraband fuchsin to France. The reason why chemical factories in Basel could maintain their position after the patents for fuchsin and other aniline colours had expired, together with the dramatic drop in prices, was due to the fact that they had already turned towards research and diversification. The University of Basel, which offered specialised education in the areas of chemistry and pharmacy, formed a further basis for innovation. The regional lack of raw materials led the Basel industry away from mass production and toward the production of specialities and refinement services. Thus it is understandable that the area of occupation of the chemical industry in Basel shifted further and further into the production of pharmaceutical agents and specialities.

\section{Industrial Growth and Scientific Research for Medical Cures}

The pharmaceutical-chemical industry in Basel has undergone an amazing development in a few decades. Fusions, purchases, takeovers, and inheritances have finally made the many big, medium and small firms into world concerns. Today, the Basel pharmaceutical-chemical industry consists of two internationally perceived global enterprises and a few smaller companies of regional or national significance. Novartis (with its spin offs) and Roche are considered global players in the pharmaceutical business.

This amazing development has of course, countless causes and a complex background. The great relevance of dye development and the resultant swift development of the chemical dye industry in Basel is a central aspect, but not the only one.

Of strategic importance for this fast growth was the position of Basel on the Rhine, which as a powerful conductor of river current, brought an abundance of water to the chemical production plants, and in turn, according to the understanding of that time, disposed easily of much soiled effluent. As well as this, the Rhine was, and still is, a transport pathway of utmost significance, especially for the delivery of raw materials such as the then vital coal and tar.

Crucially the banking system in Basel was well developed by the 19th century. A large proportion of the considerable wealth and capital of Basel families was invested into the newly growing industry via the banks, which organised the flow of capital.

Another important consideration is that the pharmaceutical-chemical industry was traditionally rooted in drug making and processing. For the dye works of textile production, many raw materials were imported and also extracted here in Basel. Purple, cochenille, indigo, and krapp were the most common. Of course, the manufacture of dye wood extracts is similar to the manufacture of alkaloid extracts in pharmaceutical production. It is therefore not surprising that this know-how led to the foundation of extract factories which then brought these standardised agents to the market. An example is the Geigy extract factory, which was founded in 1857 by the successors of the extract material and drug supplier, Johann Rudolf GeigyGemuseus (1733-1793), and later by Johann Rudolf Geigy-Merian (1830-1917) as the firm J.R. Geigy \& Cie.

The history of the individual Basel pharmaceutical-chemical enterprises, as well as the history of particular drugs and products of these companies is beyond the scope of this short article. The following products of the Basel pharmaceutical industry serve as examples to illustrate the basic changes that the sector of medicine production has experienced since industrialisation.

\section{Foxglove and Ergot}

While, for example ' $F$. Hoffmann-La Roche \&. Cie.' has been a purely pharmaceutical company since its foundation, other firms only diversified in the course of time into pharmaceutical production and in particular pharmaceutical research (Fig. 7). The company Sandoz AG was already producing a small choice of pharmaceutical products alongside the original dyes at the end of the 19th century under the name of 'Kern und Sandoz'. In particular Antipyrine, an analgesic and antipyretic. Antipyrine, a label product of the German manufacturer 'Höchst Dyeworks' but not under patent protection, could be produced legitimately. Other substances that were not subject to patent law were also produced by Sandoz at the beginning of the 20th century, e.g. Phenacetine, Phenazone, Phenolphtaleine, Resorcine and Phenobarbital. Nevertheless they brought limited economical success and remained a sideline. Only in 1917 did

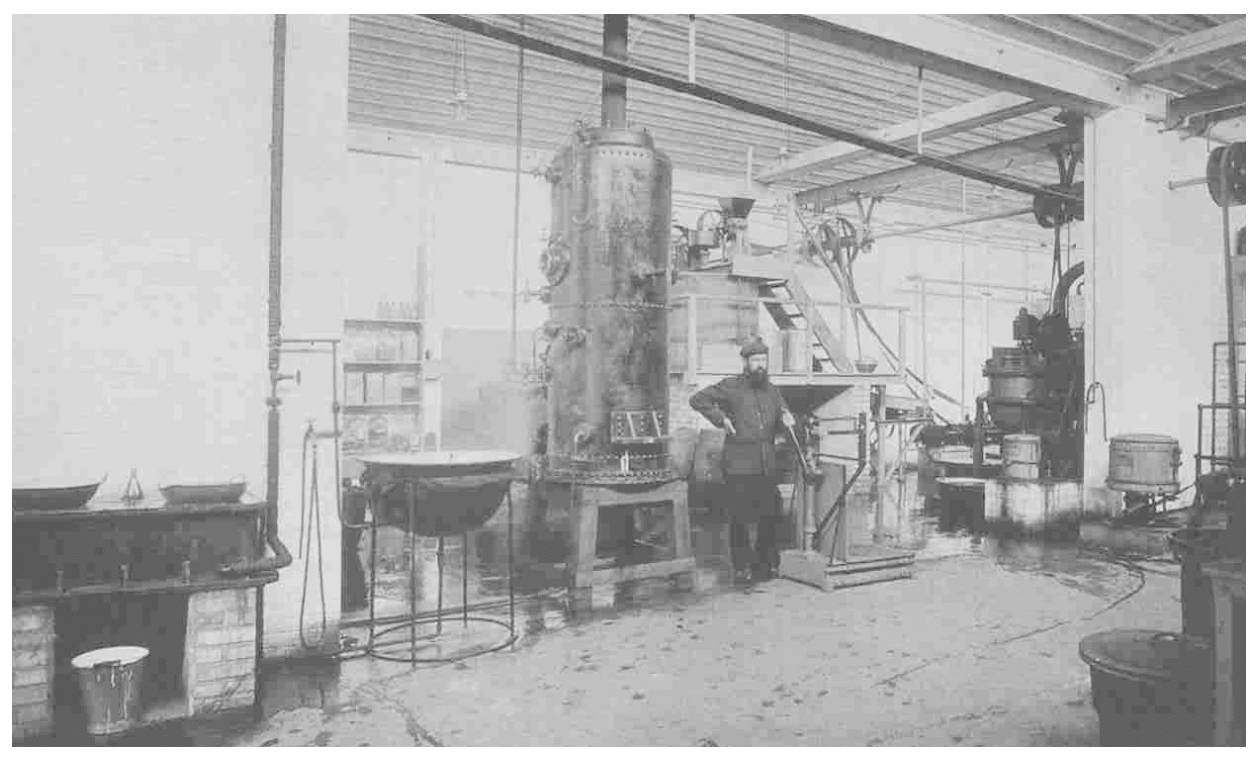

Fig. 7. F. Hoffmann-La Roche \& Cie. Production at Grenzach, early 20th century. 
the board of directors of Sandoz decide to significantly extend their pharmaceutical department. With this purpose they called on the services of the important Swiss chemist Arthur Stoll (1887-1971), who was then a member of staff of the Natural Substance Chemistry unit of the University of Munich under the 1915 Nobel Prize winner Richard Willstätter (1872-1942), to come to Basel as the director of the pharmceutical department. Stoll had a free choice of the research and work areas, but should focus on highly effective active compounds, as the management was very much aware of the problems of the major chemical industry in a country with few raw materials. It would have been preferable to scientifically examine and optimise well known products and substances, and not to gamble on unknowns, so as to minimise the entrepreneurial risk. From the work of Stoll's department, the heart-active steroid glycosides and the ergot alkaloids were of particular interest.

The effect of foxglove on the heart had been known for a long time. Only Stoll's department at Sandoz managed to isolate and quantify the active ingredients. These were then brought to market under the label Digoxin and Digitoxin. Determination of the exact dosage of these highly toxic substances only became possible after this achievement, and the path was opened to a reliable treatment of heart insufficiency. This was a great medical breakthrough.

Furthermore, the effect of ergot had been known for a long time. Stoll and members of his staff, having consulted the famous Bernese pharmakognostic and apothecary Alexander Tschirch (1856-1939), were in 1921 able to isolate and describe the first effective ingredient: Ergotamine. The derivatives of Ergotamine found broad application in both migraine treatment and obstetrics, and are to the present day an indispensable item in pharmacological therapy.

One member of Stoll's staff, the chemist Albert Hofmann (1906), later obtained the substance lysergsäurediethylamide from Ergotamine, which under the term LSD would, as a hallucinogenic, cause a sensation across the world.

At CIBA AG, the extension of the pharmaceutical department happened in a similar way. While at first many unpatented substances were synthesised and brought to market as medicine, and shown at the world exhibition in Paris in 1889, the pharmaceutical department moved in 1915 towards research and development of its own preparations, which could be sold as patented speciality medicines. Significant for this development was the Institute for Biological-Pharmacological Research, inaugurated in 1915. This was a sweeping success. In the decades that followed, preparations could be brought to market in the areas of steroid hormones, heart- circulation therapeutica, the fight against infections and finally psychotropic drugs. Many of these preparations were not only successful in sales, but were milestones in modern medicine.

\section{The Pharmaceutical Institute of the University of Basel}

Pharmacy, the science of remedies, has been known in Europe since the 13th century as an independent discipline. Before this, in the old Europe, it was not separated from medicine. In the Orient, this was not the case. Already in the 8th century at the court of the Caliph of Baghdad, pharmacy was separated from medicine. The profession of the apothecary disentangled from the profession of the doctor. Only in the 13th century, under the influence of Arabian scholars, did this separation become widespread in Europe.

The education of the apothecaries however, remained a private affair for a long time. Candidates went into apprenticeship with an apothecary; and, thereafter, extended their knowledge during their years as journeymen in other apothecaries. They became an apothecary through acceptance into a guild - in Basel the Saffron Guild - and afterwards by a permission of the Canton, which could also be linked to an exam. As early as the late Middle Ages, and even more since the 16th century, the apothecaries could extend their knowledge by visiting the lectures at the universities, especially in botany. The most famous lecturers in the 16th century in Basel were Caspar Bauhin, Theodor II Zwinger and Johann Jakob Harder. Wernhard de Lachenal, restorer of the botanical garden, already lectured from 1776-1800 at the University of Basel in Materia Medica (knowledge of remedies), chemistry and 'ars pharmaceutica' (production of remedies).

In the 19th century, pharmacy was installed as a subject in its own right at the University of Basel. Peter Merian and Christian Friedrich Schönbein were the first chemists to lecture in pharmaceutical subjects at the University of Basel; and with Johann Jakob Bernoulli there was, from 1830 onwards, for the first time a devoted Professor of Pharmacy. He read pharmaceutical chemistry, pharmacognostics (medicinal drug knowledge) and history of pharmacy. However, a unified education for apothecaries did not yet exist, even though the Swiss Apothecary Association (founded in 1843), spoke up for it vehemently. In 1868 , a few Cantons, amongst which were both Cantons of Basel, joined a concordance which set up unified and binding examination regulations. Finally in 1877 , the Swiss Confederation issued a law regarding the freedom of movement of medical personnel in Switzerland. This regulated the professional education of apothecaries as well as doctors and dentists.

In the year 1916, Professor Heinrich Zörnig from Munich took on the teaching post in Basel and applied to the Government for a massive rise in funding for the education of the pharmacists. This was approved, and the 'Pharmaceutical Department' at the Chemical Institute was transferred to the 'Haus zum Sessel' at Totengässlein 3. Thanks to a budget of $43000 \mathrm{CHF}$, the conversion into a modern institute could be realised! Professor Heinrich Zörnig remained director of the establishment until 1937, and during this time installed a modern scientific education system for the pharmacists in Basel.

\section{Tadeus Reichstein and Vitamin C - The First Steps Along a Completely New Path}

An important chapter in the pharmaceutical history of Basel began in the first half of the 20th century in Zürich. The Polish chemist Tadeus Reichstein (1897-1996) emigrated with his parents from Krakow to Switzerland and had been naturalised. He worked from 1931 at the ETH Zürich as an assistant in the Institute of Organic Chemistry with Leopold Ruzicka (1887-1976). After only two years at the ETH, Reichstein became Professor Titular, and was finally elected Professor Extraordinarius (Fig. 8).

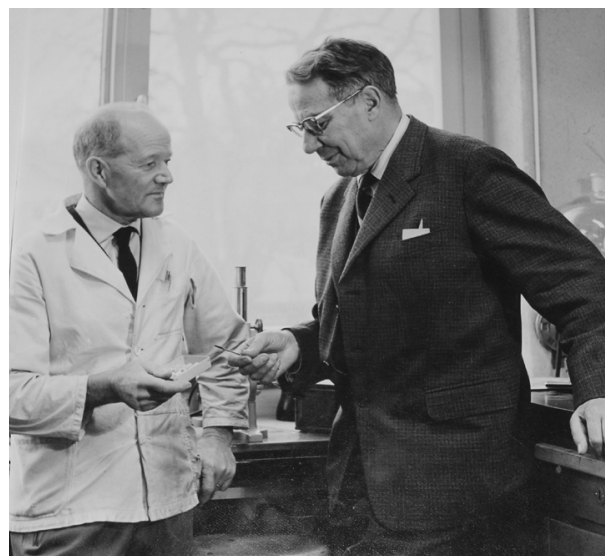

Fig. 8. Tadeus Reichstein (right) with his coworker and friend J. von Euw, in the 1950s.

His great interest in substances with significance and potential in medicine led him to choose vitamins as his special area of research. He was looking for a means to chemically synthesise Vitamin $C$. He intended to use type of sugar, L-sorbose, as a starting material. L-sorbose was known but not available on the market. What was to be done? It was a known fact that bacteria could transform sorbitol into L-sorbose. It was thought at the time that the mucousbuilding microorganisms in the vinegar substrate could help. Reichstein immedi- 
ately attempted the conversion. But the majority of the mould cultures failed and no sorbose was produced. Next, inspired by a literary work from the 19th century, Reichstein quickly constructed a new experiment. Glasses with watery sorbitol solution, yeast, and a little vinegar (the $\mathrm{pH}$ value had to be below 5 , so that no other bacteria would grow) were placed in the open for several days. Three of the glasses still contained sorbitol afterwards but three contained a sediment of white crystals. Analysis showed this to be pure L-sorbose, the urgently needed sugar.

What had happened? The process had been effected by bacteria which would later be named Acetobacter suboxydans. Quickly the bacteria were cultivated, and after a few days 100 grams of pure L-sorbose had been produced. The rest happened according to plan. Reichstein progressed along the synthetic path - acetylation and oxidation - and was quickly able to produce synthetic Vitamin C in an economical way. Reichstein later passed his patent on to the company F. Hoffmann-La Roche \& Cie., which then became the world's largest biggest manufacturer Vitamin C.

It is very impressive to see that Reichstein's highly developed means of synthesis has not been changed since that time and that to the present day, thousands of tons of Vitamin $\mathrm{C}$ are produced by the same method.

Many were surprised that Reichstein was not awarded the Nobel Prize for his work. The connection of chemistry, biology, and medicine was his major subject area. With the planned introduction of a microbiological synthetic step in an organic synthesis, he was well ahead of his time. Biotechnology only became a scientific subject many years later.

Suddenly insurmountable administrative hurdles arose at the ETH in Zürich. An appointment to Ordinarius was not possible for a Polish Jew (who had become a Swiss citizen and served in the Swiss army during World War I!) in the late thirties, and Reichstein had to leave the laboratory of Ruzicka in Zürich.

The situation in Basel was quite different; in fact the opposite of Zürich. The combination of a Social Democratic Government and strong liberal forces in Parliament (labelled as 'Red Basel' from the outside, from within 'Social Basel') led to an antifascist atmosphere and great scepticism towards the 3rd Reich among the population as well as the politicians. Certainly this was connected to the geographical situation, and the provocation of close frontiers. Although individual personalities also influenced the Basel of the time, for example the Education Director, the legendary Social Democrat Fritz Hauser or the Liberal President of the Governing Council (and chief editor of

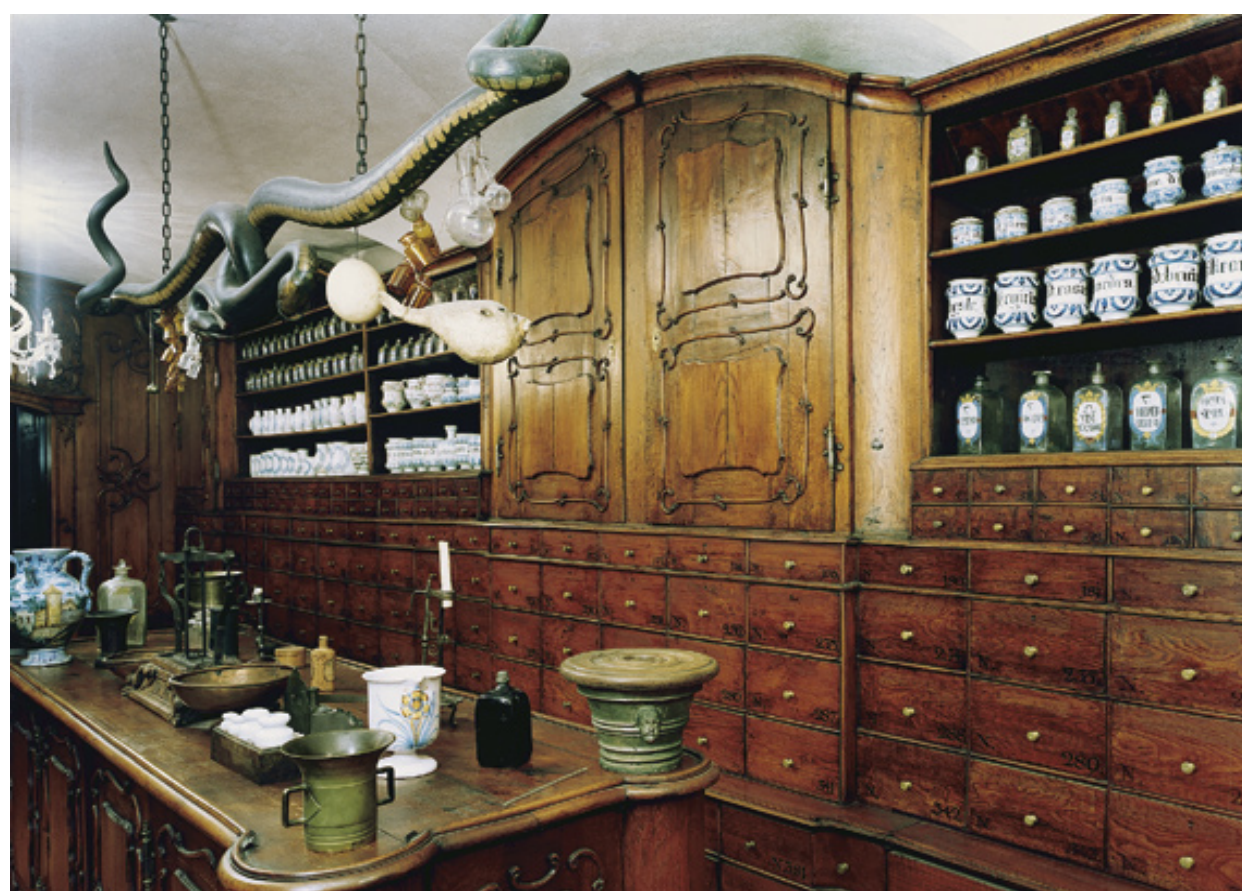

Fig. 9. The baroque pharmacy from Innsbruck, 1755. (Museum of Pharmacy of the University of Basel)

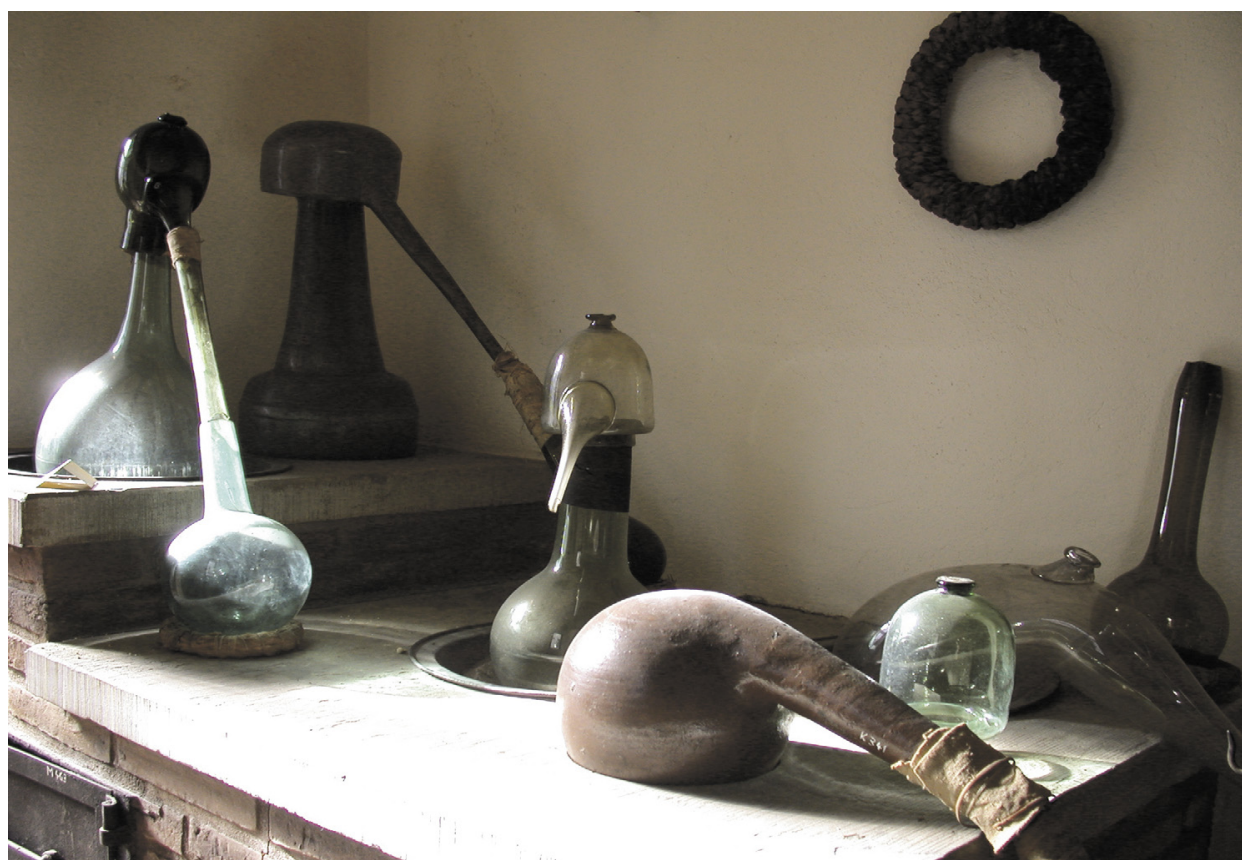

Fig. 10. The alchemistic laboratory in the ancient house chapel of the 'Haus zum Sessel'. (Museum of Pharmacy of the University of Basel)

the 'Basler Nachrichten') Albert Oeri-Preiswerk. Fritz Hauser made it possible that the Chair of Pharmacy at the University of Basel was offered to Reichstein. He accepted and from 1938 to 1950 headed the Pharmaceutical Institute at Totengässlein. His new area of research was hormones of the adrenal cortex. He succeeded in analysing the structure of Cortisone, which was of utmost importance not only in scientific terms. The industrial production of steroid hormones, to which Cortisone belongs, had already been a major subject for the pharmaceutical industry especially after World War II. For his work, Tadeus Reichstein was awarded the Nobel Prize for Medicine in 1950.

\section{Conclusion}

The list of great achievements in the industrial production of medicines by the Basel economy and industry in the 20th century is long. Pharmacy has taken on an existential meaning for Basel during the past 100 years. The concentration of pharmaceutical research and production that exists in this single region of Basel is surely unique worldwide.

Received: December 29, 2005 